\title{
Editorial: Lactic Acid Fermentation and the Colours of Biotechnology 2.0
}

\author{
Vittorio Capozzi $^{1}\left[\right.$ and Francesco Grieco ${ }^{2, *}$ (D) \\ 1 National Research Council-Institute of Sciences of Food Production (ISPA) c/o CS-DAT, \\ 71121 Via Michele Protano, Foggia, Italy; vittorio.capozzi@ispa.cnr.it \\ 2 National Research Council-Institute of Sciences of Food Production (ISPA), Via Prov.le, \\ 73100 Lecce-Monteroni, Lecce, Italy \\ * Correspondence: francesco.grieco@ispa.cnr.it; Tel.: +39-0832422612
}

check for updates

Citation: Capozzi, V.; Grieco, F. Editorial: Lactic Acid Fermentation and the Colours of Biotechnology 2.0.

Fermentation 2021, 7, 32.

https://doi.org/10.3390/ fermentation7010032

Received: 23 February 2021

Accepted: 25 February 2021

Published: 26 February 2021

Publisher's Note: MDPI stays neutral with regard to jurisdictional claims in published maps and institutional affiliations.

Copyright: (c) 2021 by the authors Licensee MDPI, Basel, Switzerland. This article is an open access article distributed under the terms and conditions of the Creative Commons Attribution (CC BY) license (https:// creativecommons.org/licenses/by/ $4.0 /)$.
Lactic acid bacteria (LAB) belong to an assorted cluster of bacteria that are protagonists of fermentative processes and bio-based solutions of interest in the different fields of biotechnological sciences, from the agri-food sector (green) up to the industrial (white), throughout the pharmaceutical (red). Even though LAB's main metabolic action is the synthesis of lactic acid as a result of the fermentation of carbohydrates, they have a great number of applications in the food and pharmaceutical industries [1-6]. In fact, LAB have a safe history of use by humans, and they are responsible for the production of many valuable molecules such as organic acids, exopolysaccharides, polyols and antimicrobial compounds. The continuous progress in the knowledge of LAB physiology and biochemistry and the availability of a great number of their complete genomic sequence have encouraged the characterization and production of an assortment of commercial starter cultures. These strains, denoted with probiotic, bio-protective and pro-technological properties, testify the biotechnological relevance of this heterogeneous bacteria class [1-6].

The Special Issue "Lactic Acid Fermentation and the Colours of Biotechnology 2.0" covers nine contributes: six original research papers and three reviews. As Guest Editors, we briefly report an overview of these contributions that included multiple aspects of LABbased innovations concerning biotechnological development, such as innovative strategies for lactic acid production, D-lactate, functional or typical fermented foods.

Indeed, three of the original research papers focused on the description of novel approaches for the biotechnological production of lactic acid/lactate. Lin et al. [7] have demonstrated lactic acid production by LAB-mediated fermentation of seaweed hydrolysates, thus confirming this substrate as a promising carbon source for microbial fermentation. Krull and coworkers [8] have studied the use of low-cost agricultural hydrolysates to produce 1-lactic acid with Lacticaseibacillus casei, showing that the industrial costs were likely to be reduced by up to $23 \%$. Concerning the D-lactate production, Wada et al. [9] evaluate the heterologous expression of a Lactobacillus bulgaricus DLDH-encoding gene under the control of a T7-driven expression system. The obtained results demonstrate the utility of the PYR strain to develop fermentation processes of pyruvate-based chemicals production.

Two original research papers deal with the development of new products enriched with nutrients and probiotics. Hyrslova and collaborators [10] have determined the speciesspecific influence of bovine colostrum and several milk bioactive compounds on the growth of ten selected strains from genera Lactobacillus, Lacticaseibacillus, Bifidobacterium and Enterococcus. Krausova et al. [11] developed and characterized new Se-enriched Streptococcus thermophilus and Enterococcus faecium strains, representing an effective selenium source essential for human health. Both tested strains demonstrated good potential for Se-enrichment and improved antioxidant properties.

Closing the primary sources, Murgia and coworkers [12] have carried out the characterization of Fruhe cheese, a typical goat and sheep cheese from Sardinia (Italy). The authors 
described the first study on the microbiological and physic-chemical characteristics of this product cheese, emphasizing its microbiological quality and the potential nutritional value.

Concerning the review papers, the contributes focused on specific bio-productions or on the significance as starter cultures. Mora-Villalobos and collaborators [4] provided a review on the industrial value of co-products of LAB-promoted lactic acid fermentations, with special attention on bacteriocins, lipoteichoic acid, and probiotics. Moreover, the authors proposed a novel multi-product process involving lactic acid and the other compounds of interest. Guerin et al. [13] reviewed the chemical composition, biosynthetic pathways and regulation mode of exopolysaccharide (EPS) produced by lactic acid bacteria, examining the impact of EPS on food quality and human health benefits since their prebiotic, antioxidant, anti-inflammatory and cholesterol-lowering activities. Capozzi et al. [14] summarized the available knowledge on LAB's oenological properties with a specific focus on their positive or negative impacts on wine quality. In particular, the characteristics of several LAB species of oenological interest were described, thus being a tool to orient the selection of new strains, to design tailored microbial starter cultures, also for traditional/typical products.

This collection contributed to improve the knowledge on the heterogeneous class of lactic acid bacteria (LAB) and recent innovative applications for lactic acid fermentation in the different biotechnological fields.

Author Contributions: Writing-original draft preparation, review and editing, V.C. and F.G. All authors have read and agreed to the published version of the manuscript.

Funding: This research received no external funding.

Acknowledgments: This work was partially supported by the Apulia Region projects: "Innovazione nella tradizione: tecnologie innovative per esaltare le qualità dei vini autoctoni spumante della murgia barese-INVISPUBA" (P.S.R. Puglia 2014/2020 -Misura 16.2); "Birra: dal campo al boccaleBE^2R" (P.S.R. Puglia 2014/2020-Misura 16.2). We would like to thank Domenico Genchi of the Institute of Sciences of Food Production-CNR for its skilled technical support provided during the realization of this work.

Conflicts of Interest: The authors declare no conflict of interest.

\section{References}

1. Senz, M.; Keil, C.; Schmacht, M.; Palinski, S.; Cämmerer, B.; Hageböck, M. Influence of Media Heat Sterilization Process on Growth Performance of Representative Strains of the Genus Lactobacillus. Fermentation 2019, 5, 20. [CrossRef]

2. Unban, K.; Kanpiengjai, A.; Khatthongngam, N.; Saenjum, C.; Khanongnuch, C. Simultaneous Bioconversion of Gelatinized Starchy Waste from the Rice Noodle Manufacturing Process to Lactic Acid and Maltose-Forming $\alpha$-Amylase by Lactobacillus plantarum S21, Using a Low-Cost Medium. Fermentation 2019, 5, 32. [CrossRef]

3. Arena, M.P.; Russo, P.; Spano, G.; Capozzi, V. Exploration of the Microbial Biodiversity Associated with North Apulian Sourdoughs and the Effect of the Increasing Number of Inoculated Lactic Acid Bacteria Strains on the Biocontrol against Fungal Spoilage. Fermentation 2019, 5, 97. [CrossRef]

4. Mora-Villalobos, J.A.; Montero-Zamora, J.; Barboza, N.; Rojas-Garbanzo, C.; Usaga, J.; Redondo-Solano, M.; Schroedter, L.; Olszewska-Widdrat, A.; López-Gómez, J.P. Multi-Product Lactic Acid Bacteria Fermentations: A Review. Fermentation 2020, 6, 23. [CrossRef]

5. Olszewska-Widdrat, A.; Alexandri, M.; López-Gómez, J.P.; Schneider, R.; Mandl, M.; Venus, J. Production and Purification of L-Lactic Acid in Lab and Pilot Scales Using Sweet Sorghum Juice. Fermentation 2019, 5, 36. [CrossRef]

6. Mangia, N.P.; Saliba, L.; Zoumpopoulou, G.; Chessa, S.; Anastasiou, R.; Karayiannis, I.; Sgouras, D.; Tsakalidou, E.; Nudda, A. Goat Milk with Different Alpha-S1 Casein Genotype (CSN1S1) Fermented by Selected Lactobacillus paracasei as Potential Functional Food. Fermentation 2019, 5, 55. [CrossRef]

7. Lin, H.-T.V.; Huang, M.-Y.; Kao, T.-Y.; Lu, W.-J.; Lin, H.-J.; Pan, C.-L. Production of Lactic Acid from Seaweed Hydrolysates via Lactic Acid Bacteria Fermentation. Fermentation 2020, 6, 37. [CrossRef]

8. Krull, S.; Brock, S.; Prüße, U.; Kuenz, A. Hydrolyzed Agricultural Residues-Low-Cost Nutrient Sources for 1-Lactic Acid Production. Fermentation 2020, 6, 97. [CrossRef]

9. Wada, K.; Fujii, T.; Inoue, H.; Akita, H.; Morita, T.; Matsushika, A. Application of a Pyruvate-Producing Escherichia coli Strain LAFCPCPt-AccBC-AceE: A Case Study for d-Lactate Production. Fermentation 2020, 6, 70. [CrossRef]

10. Hyrslova, I.; Krausova, G.; Michlova, T.; Kana, A.; Curda, L. Fermentation Ability of Bovine Colostrum by Different Probiotic Strains. Fermentation 2020, 6, 93. [CrossRef] 
11. Krausova, G.; Kana, A.; Hyrslova, I.; Mrvikova, I.; Kavkova, M. Development of Selenized Lactic Acid Bacteria and Their Selenium Bioaccummulation Capacity. Fermentation 2020, 6, 91. [CrossRef]

12. Murgia, M.A.; Deiana, P.; Nudda, A.; Correddu, F.; Montanari, L.; Mangia, N.P. Assessment of Microbiological Quality and Physicochemical Parameters of Fruhe Made by Ovine and Goat Milk: A Sardinian (Italy) Cheese. Fermentation $2020,6,119$. [CrossRef]

13. Guérin, M.; Silva, C.R.-D.; Garcia, C.; Remize, F. Lactic Acid Bacterial Production of Exopolysaccharides from Fruit and Vegetables and Associated Benefits. Fermentation 2020, 6, 115. [CrossRef]

14. Capozzi, V.; Tufariello, M.; De Simone, N.; Fragasso, M.; Grieco, F. Biodiversity of Oenological Lactic Acid Bacteria: Species- and Strain-Dependent Plus/Minus Effects on Wine Quality and Safety. Fermentation 2021, 7, 24. [CrossRef] 